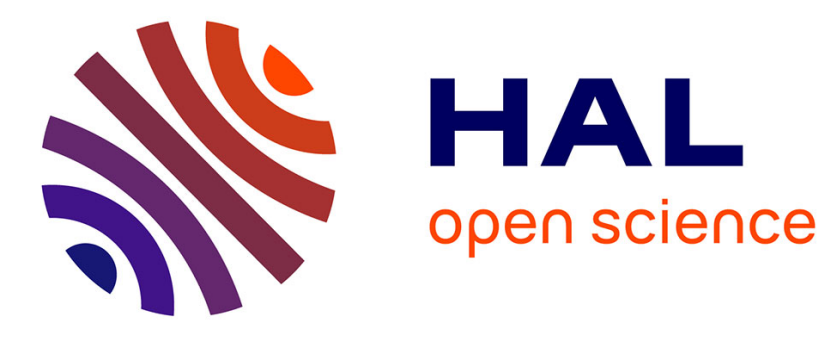

\title{
Women's perceptions of femininity after craniopharyngioma: a qualitative study
}

Raphä̈lle Eydoux, Frederic Castinetti, Magali Authier, Manon Vialle, Frédérique Albarel, Thierry Brue, Blandine Courbiere

\section{- To cite this version:}

Raphaëlle Eydoux, Frederic Castinetti, Magali Authier, Manon Vialle, Frédérique Albarel, et al.. Women's perceptions of femininity after craniopharyngioma: a qualitative study. Clinical Endocrinology, 2021, 94 (5), pp.880-887. 10.1111/cen.14378 . hal-03146106

\section{HAL Id: hal-03146106 https://hal.science/hal-03146106}

Submitted on 30 Apr 2021

HAL is a multi-disciplinary open access archive for the deposit and dissemination of scientific research documents, whether they are published or not. The documents may come from teaching and research institutions in France or abroad, or from public or private research centers.
L'archive ouverte pluridisciplinaire HAL, est destinée au dépôt et à la diffusion de documents scientifiques de niveau recherche, publiés ou non, émanant des établissements d'enseignement et de recherche français ou étrangers, des laboratoires publics ou privés. 


\section{Title:}

Women's perceptions of femininity after craniopharyngioma: a qualitative study.

Short running title:

Femininity in women with craniopharyngioma

\section{Authors:}

Raphaëlle EYDOUX ${ }^{1}$, Fréderic CASTINETTI ${ }^{2,3}$, Magali AUTHIER ${ }^{4}$, Manon VIALLE ${ }^{5}$ Frédérique ALBAREL ${ }^{2,3}$, Thierry BRUE ${ }^{2,3}$, Blandine COURBIERE ${ }^{1,6}$

${ }^{1}$ Department of Gynecology-Obstetric and Reproductive Medicine, AP-HM, Hôpital La Conception-Hôpital Nord, Marseille, France.

${ }^{2}$ Assistance Publique-Hôpitaux de Marseille (AP-HM), Department of Endocrinology, Hôpital de la Conception, Centre de Référence des Maladies Rares de l'hypophyse HYPO, Marseille, France.

${ }^{3}$ Aix-Marseille Univ, INSERM, U1251, Marseille Medical Genetics (MMG), Institut Marseille Maladies Rares (MarMaRa), Marseille, France.

${ }^{4}$ Faculté des sciences médicales et paramédicales - Timone, Département de Médecine Générale, 27 Boulevard Jean Moulin, Aix-Marseille Université, 13385 Marseille, France. ${ }^{5}$ Centre Norbert Elias-UMR 8562, École des Hautes Études en Sciences Sociales, CNRS, Aix Marseille Univ, Marseille, France.

${ }^{6}$ Aix Marseille Univ, IMBE, CNRS, IRD, Avignon Université, Marseille, France.

\section{Corresponding author}

Raphaelle EYDOUX

Department of Gynecology-Obstetric and Reproductive Medicine, AP-HM, Hôpital La Conception, 147 Boulevard Baille, 13385 Marseille Cedex 05, France

Mail : raphaelle.eydoux@gmail.com

Key words: Craniopharyngioma, qualitative study, femininity, sexuality, infertility, body image, intimacy. 


\section{Summary}

Background: Previous quantitative studies have shown a reduced quality of life in patients treated for craniopharyngioma (CP). However, few have assessed their sexual quality of life and other issues related to patient intimacy have not yet been addressed. Standardized questionnaires limit the approach to sexuality and the exploration of patient experiences. A qualitative study, which allows in-depth analysis, may represent an interesting approach to explore intimacy in women with a history of $\mathrm{CP}$.

Objective: To assess the impact of a $\mathrm{CP}$ history on femininity and relationships in women.

Design and patients: A qualitative study with semi-structured interviews was conducted with 15 adult women treated for CP during childhood, adolescence or at childbearing age up to 40 years of age. Interviews were audio recorded, anonymized and transcribed literally. Data analysis was carried out with an inductive approach according to the grounded theory method.

\section{Results}

Three main themes were identified: (1) Apparent changes leading to altered selfperception that may impact on femininity and generate lower self-esteem; (2) Managing the hidden disabilities of the disease inducing a need for permanent control; (3) Building parenthood and couple relationships: coping with sexual dysfunction and infertility.

\section{Conclusions}

Our study highlighted alterations in self-perception and femininity due to body change and disability resulting from CP treatment, impacting both couple and social relationships. Interviewing women who underwent CP surgery at different ages highlighted specific needs and different expectations of medical professionals which emphasize the importance of offering both global and personalized care. 


\section{Introduction}

Craniopharyngioma (CP) is a rare benign slow-growing epithelial tumor of the sellar and suprasellar region that is derived from embryonic remnants of Rathke's pouch. ${ }^{1} \mathrm{CP}$ accounts for 3 to $5 \%$ of all intracranial tumours, corresponding to 0.5 to 2 cases per 1 million person-years, with a bimodal age distribution at 5-14 and 50-74 years. ${ }^{2,3}$ Due to its location and treatment, CP can be responsible for visual, neuropsychological and endocrine sequelae that can impair patient quality of life. ${ }^{4-9}$ The most frequent endocrine impairments are anterior pituitary insufficiency, diabetes insipidus and hypothalamic obesity. ${ }^{10-12}$ Pubertal induction and medically assisted reproduction (MAR) may be required in $\mathrm{CP}$ patients as gonadotrophin deficiency affects puberty, sexuality and fertility, depending on the gender and age at which CP treatment occurs. ${ }^{13,14}$ As a result, the intimate relationships of women with $\mathrm{CP}$ may be affected and they may also experience reproductive difficulties.

Several quantitative studies have previously demonstrated a reduced quality of life in adults who underwent surgery for CP in childhood. ${ }^{15-18}$ Only a few studies have evaluated the intimacy of patients treated during childhood or adolescence, ${ }^{19-21}$ reporting decreased psychosexual function and a lower rate of sexual activity compared to the general population. In these quantitative studies, standardized questionnaires may have limited the evaluation of sexual quality of $\operatorname{life}^{22}$ and have thus failed to allow an in depth exploration of patient experiences. A qualitative study, which has the benefit of greater understanding rather than systematically describing ${ }^{23}$ appears to be the best approach to explore intimacy and, to our knowledge, has not to date been carried out in women with a history of CP. Moreover, we considered that it would be relevant to study women who were treated during childhood, adolescence and childbearing years, since these issues may vary with age at diagnosis.

The aim of our study was to assess the impact of $\mathrm{CP}$ on femininity and couple relationships in adult women, with the goal of finding ways to improve the overall care of these patients. 


\section{Subjects and methods}

We conducted 15 in-depth, semi-structured interviews between March 2019 and April 2020. Interviews were carried out in French. Women were recruited from the Reference Centre for Rare Pituitary Diseases and the Centre of Reproductive Medicine at a University Teaching Hospital (Marseille, France) during a follow-up consultation. We included women operated on for CP from paediatric age to 40 years-old. Sample size was determined by the principle of data saturation. The interviews were conducted either at the hospital or at their home depending on their patients' personal convenience. A phone interview was proposed for women who were unable to meet face to face. Interviews were conducted by one researcher (RE) using a guide composed of open-ended questions. This guide evolved, being reworked after each interview to improve its relevance, and consisted of three parts:

- Family and socio-professional situation,

- History of CP: age at diagnosis, post-operative sequelae, treatments implemented and body changes.

- Emotional and intimate life: women who were operated on during childhood or adolescence were asked about their experience of puberty and their first sexual intercourse. The rest of the interview was conducted in a very personalized way according to each person's profile: the impact on couple relationships and sexuality, any experience of infertility and patient access to parenthood.

We ended the interview by asking women to rate their general well-being on a scale of 0 to 10. Finally, women gave us feedback on their personal care. The interviews were audio recorded then transcribed verbatim by the same researcher (RE) and were anonymized before commencing the analysis. The interviews lasted between 25 and 75 min (mean 39 $\min +/-12.1)$.

Data analysis was carried out using an inductive approach according to the grounded theory method which aims to produce theories from empirical material. ${ }^{24}$ First, a microanalysis was carried out separately by two researchers (RE and MA): codes were compared and did not differ between the two investigators. Codes were then pooled and organized to create categories. Finally, these categories were connected to each other in order to bring out the main themes of this analysis, new theories anchored in the stories of the women interviewed. Results were translated from French to English after analysis.

The study was approved by the local ethical committee of Aix-Marseille University and participants gave their informed consent. 


\section{Results}

Interviews were conducted with 15 women. Mean age was 38 years (from 25 to 51 years $+/-7.5), 6$ women underwent surgery during childhood, 4 during adolescence and 5 between the age of 28 and 40 years. 13 women had panhypopituitarism, the remaining two had at least gonadotropic deficiency thus every women received hormone replacement therapy (HRT). Subjects' clinical characteristics are summarized in Table 1.

Three main themes emerged from interviews: (1) Apparent changes leading to altered self-perception; (2) Managing the hidden disabilities of the disease; (3) Building parenthood and a couple relationship: coping with infertility and sexual dysfunction.

\section{Apparent changes leading to altered self-perception}

Apparent changes. During the postoperative period, women may have been confronted with multiple changes. Body changes such as significant weight gain or ophthalmic impairments were the first to be addressed by women as these were the most visible signs of the disease:

P3 "People ask questions really quickly because it's physical."

Women expressed difficulties in accepting these changes, especially in the case of obesity which was characterized as an uncontrollable burden:

P8 "Gaining weight without eating is really difficult to manage, it doesn't make any sense".

Behavioral changes were also reported, such as a loss of self-control, which can affect the subject's relationship with food due to lack of satiety or the management of emotions, leading to misunderstandings between the subject and their family:

P13 “And then I'm going to have mood swings, I don't know why. My relatives don't understand very well".

In addition, most women noticed a loss of energy and increased tiredness resulting in a need to change their normal habits:

P11 "I was a very dynamic person. Now when I wake up, I'm already tired."

Alterations in self-perception. In the face of these changes, some women developed an altered self-perception, with the specific nature of the alteration dependent on the age at diagnosis. Women who were operated on as adults were particularly affected by the sudden change from their previous condition, which they often compared to a metamorphosis:

P14 "We are a little bit left alone in front of this metamorphosis. It was very difficult to see myself changing mentally and physically."

For some subjects, these changes may have resulted in a loss of self-recognition:

P15 "Sometimes I passed in front of the mirror and I was scared because I felt like it wasn't me. I felt like I was trapped in a body that did not belong to me."

This loss of self-recognition has also been reported in some cases by women with pituitary deficits as they felt that their treatments took control of their feelings:

P12 "I feel like everything is distorted, it's like I don't have feelings anymore."

The specific issue of "developing a woman's body" was also raised by subjects who required induction of puberty. Some considered it as good fortune, allowing them to become women:

P2 "For me, the craniopharyngioma made me become the woman I was meant to be." In one case, HRT resulted in the development of an 'artificial body': 
P1 "The problem is that I don't feel natural. For me, my body is artificially made."

Finally, one woman expressed disappointment with the failure to obtain satisfactory secondary sexual characteristics:

P4 "I had almost no chest and zero pubic hair. It really didn't work."

Overall, most women reported having a poor body image, which may have been responsible for low self-esteem or ill-being, with a mean well-being score of 5.7+/- 1.9 out of 10 .

This poor body image in some cases impacted on their femininity and may also have constituted an obstacle to forming relationships:

P4 "I preferred not having a relationship rather than showing my body as it was. I got used to the idea of being single."

\section{Managing the hidden disabilities of the disease}

In addition to the body changes previously noted, women raised issues of the "hidden disabilities" caused by CP treatment which may have equally impacted their quality of life and their relationships.

For some women, the disease engendered a need for permanent control resulting in them no longer being able to be carefree:

P10 "There is no longer any lightness of life."

This feeling was reported in some cases by women who developed obesity and who emphasized the difficulty of losing weight despite dietary restrictions:

P12 "Weight is a constant struggle for me."

These restrictions may also have resulted in social barriers, impacting their relationships: P1 "Going to restaurants is becoming a social problem for me."

This has also been reported by women with pituitary deficits, who have characterized their daily treatments as an "invisible disability" since they require permanent forethought and constant situational adjustment:

P1 "The thing with my disease is that I can't accept the unexpected. Everything has to be planned."

For some, the need for taking medication is a daily reminder of their illness:

$P 9$ "It's like something hovering over my life that I'm trying to forget but always reminds me that it's there."

Finally, these daily requirements in some cases created apprehension about frightening a potential partner:

P2 "I was afraid that all my treatments would scare someone else."

\section{Building parenthood and couple relationships: coping with sexual dysfunction and infertility.}

Sexual dysfunction. Women raised the issues of vaginal dryness and lack of libido and complained about the difficulty in finding adequate HRT. While a few women were satisfied with the management of vaginal dryness, most of them expressed dissatisfaction or even poor tolerance of these treatments and reported no improvement in their libido: $P 7$ "There is one treatment that I can't tolerate, and the pill dries me up completely." As a result, vaginal dryness and lack of libido may have affected their well-being and the couple's sexual health:

$P 9$ "There is a bit of an obligation within the couple, you know, that there will be sexual intercourse." 
Nevertheless, different approaches to sexuality were noted. Women who were operated on during childhood reported that they were not informed about what "normal sexuality" is and that they therefore had no basis for comparison, unlike those subjects who were operated on in adulthood:

P1 "People who have had sex before, well, they know what it is. I don't even know what libido is."

For women who underwent surgery during adolescence, the disease may have caused a delay in the usual course of events leading to sexual initiation being later when compared to other adolescents:

P10 "When you are young you have flirtations, but everything was blocked for me."

Therefore, among the 10 women operated on during childhood or adolescence, four were still virgins (aged 25, 41, 43 and 51 years old), and the mean age of first sexual intercourse was $20+/-2.5$ years old.

Among all the women interviewed, only a few reported having developed a fulfilling sexuality. For them it was a real co-learning experience, requiring patience from their partner:

P7 "Finally, I learned to discover my own pleasure when I met someone great."

For women who were unsatisfied despite HRT, lubricants could have been a useful alternative but also require planning that might impact on the spontaneity of sexual intercourse.

Finally, most women expressed resignation in the search for a fulfilling sexuality, mainly because of a lack of libido, and reported having learned to do "without" and to develop their sexuality for the benefit of their partner:

P13 "We do it anyway, we have to relieve him."

Coping with infertility. Infertility induced by hypogonadotropic hypogonadism was experienced in very different ways. Most of the women interviewed considered motherhood as an intrinsic element of being a woman and felt their infertility as a disability that impacted their femininity:

P11 "You know, a woman is a life bearer, she gives life."

As a result, infertility may have created a feeling of guilt and an apprehension concerning frightening their partner:

P5 "That's what scared me a little bit, to think that maybe he wouldn't stay with me if I couldn't bear a child."

Resorting to MAR represented a coping strategy for some women, who were hoping for parenthood, and was perceived in different ways. Women operated on during childhood or adolescence reported that they were psychologically prepared for infertility, and that this helped them to accept the idea of undergoing MAR, unlike those who underwent surgery later:

P5 "Well, I've known it for so long, I thought it was like that."

However, some women felt time pressure and the fear of not being able become a parent: P3 "We know that we have to find someone, then build a case and that if our situation is not considered stable enough, the case won't be successful."

Finally, for women who planned a pregnancy, MAR was a difficult but optimistic project for the couple:

P11 "It's not easy for us to pursue MAR as an option but when you are well taken care of, it's comforting, and it gives you hope."

In the case of live birth after MAR, some women considered this as having achieved a personal accomplishment that also aided in strengthening their femininity: 
P6 "It's quite a victory over the disease to have had babies. And I don't know if it's being a mom, but I feel more feminine."

Different experiences of parenthood. Approaching the issue of infertility allowed some women to question their relationship to parenthood. Indeed, women in some cases expressed doubts about their ability to take care of a child because of their disease:

P10 "I wondered if I could really support this role. Sometimes I even find it hard to manage myself, so with a child, it's not easy."

Other women simply expressed that they had never felt the desire to have children. Women who had children before their intervention considered themselves fortunate to have had the time to become mothers which allowed them to distance themselves from infertility. For one of them, the illness may also have been motivation for a new pregnancy:

P11 "It's for my daughter, she must have someone to lean on. I lived it with my disease, it's good to have siblings."

Women who expressed a sense of helplessness regarding their disease may have developed compensatory attitudes, for example creating another form of parenthood:

P4 "We live together with my mother; she means everything to me. And maybe I felt the desire to have children when I saw my nieces and nephews. But at the same time, I took care of them so much that I consider them a bit like my own children."

Adjustments to couple relationship. Women who established a couple relationship agreed that it was necessary to explain the disease to their partner in order for them to accept the burden and to show support and understanding. In the end, some women considered that the disease had actually contributed to strengthening their relationship: P15 "You know, between everyday life, work, my little girl, we had other priorities. With what happened, I think we realized that we could have lost each other and then, our relationship became our priority."

For others, the disease created an imbalance within the couple, with the feeling of being in a position of weakness:

P12 "He's not very forgiving, he always asks for just as much. And it's complicated for me to be the one to tell him to stop because it reminds me of the fact that I can't give any more."

Finally, some expressed that there were misunderstandings within the couple and a lack of support which could have led to relationship breakdown:

P14 "I didn't have the support I needed and there wasn't that level of attention, that tenderness." 


\section{Discussion}

To our knowledge, we report here the first qualitative study about femininity and couple relationships in adult women treated for CP. Previous quantitative studies that have been conducted on CP patient intimacy have essentially focused on sexuality. In a study using the Medical Outcomes Study sexual functioning survey, Hildalgo et al., reported a lower proportion of sexually active individuals, compared to the general population, in 22 young adults (9 women, 13 men) with a history of CP in childhood ${ }^{21}$. However, global sexual functioning was not different compared to the general population, though its assessment may have been biased by the use of a standard questionnaire in a small study cohort of both women and men ${ }^{22}$. In our study we chose to focus on women, since we hypothesized that intimacy sequelae are most likely gender specific. Our qualitative study allowed a deeper analysis of women's intimacy, focusing on the factors that may have impacted their femininity and their relationships.

We first identified a phenomenon of an altered self-perception in response to physical and behavioural changes engendered by $\mathrm{CP}$ treatment. This feeling was reported by women who were operated in adulthood, who compared these changes to a traumatic metamorphosis. This change from the existing condition, with a "before and after" the disease, has also been described in other endocrine diseases as leading to a loss of selfrecognition ${ }^{25,26}$. Notably, the development of obesity emerged as a major factor in decreased self-esteem, which is in agreement with the results of other studies conducted on obesity ${ }^{27}$ and on quality of life of patients with $\mathrm{CP}^{17}$.

Behavioural disturbances, previously reported in other studies of CP patients, ${ }^{19,28}$ mainly concerned a loss of self-control with unexpected reactions leading to misunderstandings in their relationships. Alterations in self-perception were also noticed by women who required induction of puberty, reporting very different experiences of the process leading to developing a "woman's body". Quantitative studies have previously been conducted in patients with congenital hypogonadism in order to assess the influence of pubertal management on sexuality, ${ }^{29}$ reporting that age at first intercourse was related to age at onset of puberty. In our study, women were not always able to recall precisely age at onset of puberty but age at first intercourse seemed to be associated with body image, with obesity having a major negative impact. Finally, among the 10 women who were operated on during childhood or adolescence, four were still virgins at the time of the study and the mean age of the first sexual intercourse was $20+/-2.5$ years old, which is delayed compared to the latest data on first intercourse for girls in France, which is reported to be 17.6 years. ${ }^{30}$

In addition to the influence of body image, women emphasized the difficulty in managing vaginal dryness and a lack of libido despite HRT, which has also been reported in women with congenital hypogonadotropic hypogonadism. ${ }^{31}$ Lack of libido, which had been noted in a previous study on CP patients, ${ }^{32}$ was the most frequently reported item and had the most impact on the couple's sexual health.

Finally, women have also addressed their experience of infertility. While some of them may have felt that this impacted on their femininity, others accepted it more easily, either because they already had children or because they did not have plans to conceive. For women who did wish to have children, resorting to MAR may have been difficult but was also a source of hope, with the real possibility of having a live-birth. ${ }^{33,34}$ Considering the subject of infertility also allowed women to reflect on parenthood. While for some women 
the disease may have been perceived as a hindrance to caring for a child, others saw it as motivation for a new pregnancy.

In this study we interviewed women who underwent surgery at different ages: in childhood, adolescence or adulthood. On the one hand, this may have constituted a bias, by interviewing populations that, in some aspects, were not comparable. On the other hand, this allowed the emergence of common themes while also identifying specificities related to the subject's age at intervention. Moreover, satisfaction with HRT and the evaluation of its efficacy may also have been biased, as some women acknowledged that they had discontinued treatment early. Though the recruitment was consecutive from the clinic (avoiding the risk of patients' selection on a positive or negative outcome), the monocentric nature of the study did not allow to determine a potential impact of ethnicity on the outcome. Finally, all the women interviewed in our study were heterosexuals, therefore we did not study the impact of CP on the intimate life of women with a different sexual orientation.

In conclusion, in this study we showed that women with CP are affected in terms of both their femininity and in their relationships, as $\mathrm{CP}$ modifies body image, sexuality and affects women's reproductive potential. Qualitative studies offer a new approach to determine the expectations of a population exposed to a pathology, the results of which could help to meet their needs and improve their therapeutic education. In fact, women interviewed in our study stated that they had different expectations of medical professionals, especially during transitional states such as puberty, initiation to sexuality and childbearing years, which is consistent with women's feelings reported in other endocrine pathologies such as congenital adrenal hyperplasia. ${ }^{35}$ They notably insisted on the difficulty of addressing sexuality issues during education sessions and suggested a more individualized care. Our study emphasizes the importance of these issues in women's lives and reinforces the need for offering comprehensive, multidisciplinary but also personalized care for women treated for CP. Similar studies should now be conducted in men with CP since they are equally concerned by the issues raised here and may have different experiences of CP. 
Acknowledgements: The authors wish to thank Ian Darby (Editing biomed) for English editing.

Conflict of interest: The authors have no conflicting interests or disclosures to declare. Funding: None

Data availability statement: Data collected for the study, including individual participant data and a data dictionary defining each field in the set, will be made available upon reasonable request to the corresponding author.

\section{Legend to table 1}

Clinical characteristics of participants. MAR= Medically Assisted Reproduction, NR= Not requested. Well-being score: Participants were asked to rate their general well-being on a scale of 0 to 10 .

a Participants P4, P9 and P14 discontinued HRT early.

b None of the childless women had initiated MAR procedures. 


\section{References}

1. Müller HL. Craniopharyngioma. Endocr Rev. 2014;35(3):513-543.

2. Bunin GR, Surawicz TS, Witman PA, Preston-Martin S, Davis F, Bruner JM. The descriptive epidemiology of craniopharyngioma. J Neurosurg. 1998;89(4):547-551.

3. Müller HL. Diagnostics, Treatment, and Follow-Up in Craniopharyngioma. Front Endocrinol. 2011;2.

4. Zoicas F, Schöfl C. Craniopharyngioma in adults. Front Endocrinol. 2012;3:46.

5. Erfurth EM. Endocrine aspects and sequel in patients with craniopharyngioma. $J$ Pediatr Endocrinol Metab JPEM. 2015;28(1-2):19-26.

6. Puget S. Treatment strategies in childhood craniopharyngioma. Front Endocrinol. 2012;3:64.

7. Bogusz A, Müller HL. Childhood-onset craniopharyngioma: latest insights into pathology, diagnostics, treatment, and follow-up. Expert Rev Neurother. 2018;18(10):793-806.

8. O'steen L, Indelicato DJ. Advances in the management of craniopharyngioma. F1000Research. 2018;7.

9. Puget S, Garnett M, Wray A, et al. Pediatric craniopharyngiomas: classification and treatment according to the degree of hypothalamic involvement. $J$ Neurosurg. 2007;106(1 Suppl):3-12.

10. Mortini P. Craniopharyngiomas: a life-changing tumor. Endocrine. 2017;57(2):191-192.

11. Karavitaki N, Cudlip S, Adams CBT, Wass JAH. Craniopharyngiomas. Endocr Rev. 2006;27(4):371-397.

12. Müller HL, Faldum A, Etavard-Gorris N, et al. Functional capacity, obesity and hypothalamic involvement: cross-sectional study on 212 patients with childhood craniopharyngioma. Klin Padiatr. 2003;215(6):310-314.

13. Geffner ME. Hypopituitarism in childhood. Cancer Control J Moffitt Cancer Cent. 2002;9(3):212-222.

14. Thompson CJ, Costello RW, Crowley RK. Management of hypothalamic disease in patients with craniopharyngioma. Clin Endocrinol (Oxf). 2019;90(4):506-516.

15. Heinks K, Boekhoff S, Hoffmann A, et al. Quality of life and growth after childhood craniopharyngioma: results of the multinational trial KRANIOPHARYNGEOM 2007. Endocrine. 2018;59(2):364-372.

16. Dekkers OM, Biermasz NR, Smit JWA, et al. Quality of life in treated adult craniopharyngioma patients. Eur J Endocrinol. 2006;154(3):483-489.

17. Yano S, Kudo M, Hide T, et al. Quality of Life and Clinical Features of LongTerm Survivors Surgically Treated for Pediatric Craniopharyngioma. World Neurosurg. 2016;85:153-162.

18. Patel KS, Raza SM, McCoul ED, et al. Long-term quality of life after endonasal endoscopic resection of adult craniopharyngiomas. J Neurosurg. 2015;123(3):571-580.

19. Poretti A, Grotzer M, Ribi K, Schönle E, Boltshauser E. Outcome of craniopharyngioma in children: Long-term complications and quality of life. Dev Med Child Neurol. 2004;46:220-229.

20. Clopper RR, Meyer WJ, Udvarhelyi GB, et al. Postsurgical IQ and behavioral data on twenty patients with a history of childhood craniopharyngioma. Psychoneuroendocrinology. 1977;2(4):365-372.

21. Hidalgo ET, Orillac C, Kvint S, et al. Quality of life, hypothalamic obesity, and sexual function in adulthood two decades after primary gross-total resection for childhood craniopharyngioma. Childs Nerv Syst ChNS Off J Int Soc Pediatr Neurosurg. 2020;36(2):281-289. 
22. Arrington R, Cofrancesco J, Wu AW. Questionnaires to measure sexual quality of life. Qual Life Res Int J Qual Life Asp Treat Care Rehabil. 2004;13(10):1643-1658.

23. Glaser BG, Strauss AL. The discovery of grounded theory: strategies for qualitative research. New Brunswick: Aldine; 2009

24. Lejeune C. Manuel d'analyse qualitative. Analyser sans compter ni classer. De Boeck; 2014.

25. Estcourt S, Vaidya B, Quinn A, Shepherd M. The impact of thyroid eye disease upon patients' wellbeing: a qualitative analysis. Clin Endocrinol (Oxf). 2008;68(4):635639.

26. Sibeoni J, Manolios E, Verneuil L, Chanson P, Revah-Levy A. Patients' perspectives on acromegaly diagnostic delay: a qualitative study. Eur $J$ Endocrinol. 2019;180(6):339-352.

27. Doll HA, Petersen SE, Stewart-Brown SL. Obesity and physical and emotional well-being: associations between body mass index, chronic illness, and the physical and mental components of the SF-36 questionnaire. Obes Res. 2000;8(2):160-170.

28. Pascual JM, Prieto R, Castro-Dufourny I, et al. Craniopharyngiomas Primarily Involving the Hypothalamus: A Model of Neurosurgical Lesions to Elucidate the Neurobiological Basis of Psychiatric Disorders. World Neurosurg. 2018;120:e1245e1278.

29. Carel J-C, Elie C, Ecosse E, et al. Self-esteem and social adjustment in young women with Turner syndrome--influence of pubertal management and sexuality: population-based cohort study. J Clin Endocrinol Metab. 2006;91(8):2972-2979.

30. Bajos N, Rahib D, Lydié N. Genre et sexualité. D'une décennie à l'autre. Baromètre santé 2016. Saint-Maurice : Santé publique France. 2018.

31. Oyarzún MFG, Castelo-Branco C. Sexuality and quality of life in congenital hypogonadisms. Gynecol Endocrinol. 2016;32(12):947-950.

32. Larijani B, Bastanhagh MH, Pajouhi M, Kargar Shadab F, Vasigh A, Aghakhani S. Presentation and outcome of 93 cases of craniopharyngioma. Eur $J$ Cancer Care (Engl). 2004;13(1):11-15.

33. Hayashi M, Tomobe K, Hoshimoto K, Ohkura T. Successful pregnancy following gonadotropin therapy in a patient with hypogonadotropic hypogonadism resulting from craniopharyngioma. Int J Clin Pract. 2002;56(2):149-151.

34. Volz J, Heinrich U, Volz-Köster S. Conception and spontaneous delivery after total hypophysectomy. Fertil Steril. 2002;77(3):624-625.

35. Engberg H, Möller A, Hagenfeldt K, Nordenskjöld A, Frisén L. The experience of women living with Congenital Adrenal Hyperplasia: impact of the condition and the care given. Clin Endocrinol (Oxf). 2016;85(1):21-28. 


\begin{tabular}{|c|c|c|c|c|c|c|c|c|c|c|c|}
\hline Participants & $\begin{array}{l}\text { Age at } \\
\text { surgery } \\
\text { (years) }\end{array}$ & $\begin{array}{c}\text { Age at } \\
\text { interview } \\
\text { (years) }\end{array}$ & $\begin{array}{c}\text { Obesity } \\
(\text { BMI } \\
>30 \\
\left.\mathbf{k g} / \mathbf{m}^{2}\right) \\
\end{array}$ & $\begin{array}{c}\text { Pan- } \\
\text { hypopituitarism }^{\text {a }}\end{array}$ & $\begin{array}{l}\text { Diabetes } \\
\text { insipidus }\end{array}$ & $\begin{array}{c}\text { Visual } \\
\text { impairment }\end{array}$ & $\begin{array}{l}\text { Pubertal } \\
\text { induction }\end{array}$ & $\begin{array}{c}\text { First } \\
\text { intercourse } \\
\text { (years) }\end{array}$ & $\begin{array}{l}\text { Marital } \\
\text { status }\end{array}$ & Children $^{b}$ & $\begin{array}{c}\text { Well } \\
\text { being } \\
\text { score /10 }\end{array}$ \\
\hline P1 & 6 & 41 & Yes & Yes & Yes & Yes & Yes & Virgin & Single & 0 & 5 \\
\hline $\mathrm{P} 2$ & 17 & 37 & Yes & Yes & Yes & No & Yes & 23 & Married & 3 (MAR) & 8 \\
\hline P3 & 5 & 30 & No & Yes & Yes & Yes & Yes & 21 & Single & 0 & 3 \\
\hline P4 & 4 & 51 & Yes & Yes & No & Yes & Yes & Virgin & Single & 0 & 7 \\
\hline P5 & 5 & 30 & No & Yes & Yes & No & Yes & 19 & $\underset{\text { relationship }}{\text { In a }}$ & 2 (MAR) & 8 \\
\hline P6 & 8 & 33 & Yes & Yes & Yes & No & Yes & 22 & Married & 2 (MAR) & 6 \\
\hline P7 & 7 & 36 & Yes & Yes & Yes & Yes & Yes & 16 & $\underset{\text { relationship }}{\text { In a }}$ & 0 & 5 \\
\hline P8 & 16 & 25 & Yes & Yes & Yes & Yes & Yes & Virgin & Single & 0 & 7 \\
\hline P9 & 14 & 43 & No & Yes & Yes & No & No & Virgin & $\underset{\text { relationship }}{\text { In a }}$ & 0 & 6 \\
\hline P10 & 15 & 40 & No & Yes & Yes & No & No & 19 & Single & 0 & 7 \\
\hline P11 & 28 & 36 & No & No & Yes & No & NR & NR & Married & 1 (MAR) & 2 \\
\hline P12 & 40 & 42 & No & Yes & Yes & No & NR & NR & Married & 2 (MAR) & 3 \\
\hline P13 & 36 & 43 & No & Yes & Yes & No & NR & NR & $\begin{array}{l}\text { In a } \\
\text { relationship }\end{array}$ & $\begin{array}{l}3 \text { (before CP } \\
\text { surgery) }\end{array}$ & 5 \\
\hline P14 & 40 & 51 & Yes & Yes & Yes & No & NR & NR & Single & $\begin{array}{l}1 \text { (before CP } \\
\text { surgery) }\end{array}$ & 7 \\
\hline P15 & 29 & 32 & Yes & No & Yes & No & NR & NR & Married & $\begin{array}{c}1 \text { (before } \mathrm{CP} \\
\text { surgery) }\end{array}$ & 7 \\
\hline
\end{tabular}

Table 1. Clinical characteristics of participants. 